\title{
PENINGKATAN HASIL BELAJAR MENGGIRING BOLA DENGAN METODE INQUIRY
}

\author{
Muh. Yusril \\ Email:yusrilmuh.777@gmail.com \\ Orcid Id: https://orcid.org/0000-0001-9896-2811 \\ Article received \\ :2020-12-20 \\ Review process : :2021-06-15 \\ Article published : :2021-06-27
}

\begin{abstract}
This research aims to find out whether students' learning outcomes of Dribbling Learning In Football Games can be improved by using inquiry method. Instruments used in this research namely dribbling work tests on football games and motivational observation, cooperation and development of football movements.This research is Class Action Research (CAR). As for the subjects in this study are grade VIII 8students that consists of 28 students consisting of 13women and 15 men.The results of the study can be concluded that efforts to improve the results of dribbling learning in football games with inkuiry methods in grade VIII students of SMP Negeri 8 Palopo are characterized by an increase in the average grade of students. The average grade of students in pretinence activities was 70.67 with a completion percentage of $42.86 \%$. The condition increased the average grade of students in cycle I by 73.74 and the completion percentage by $60.71 \%$. However, the increase has not yet reached the previously set target. Then after moving on to cycle II the average grade of student football increased again by 80.82 with a completion percentage of $85.71 \%$. This indicates that the previously set target has been reached so that research is stopped in cycle II. The dribbling ability in the game of learner football is increased by being marked by all students completed KKM (Minimum Completion Criteria) which is 75.
\end{abstract}

Keywords : Dribbling,Football, Inkuiry Method

\begin{abstract}
Abstrak: Penelitian ini bertujuan untuk mengetahui dengan metode inkuiry apakah hasil belajar siswa dapat meningkat dengan pembelajaran menggiring bola pada permainan sepakbola Instrumen yang digunakan yaitu tes unjuk kerja menggiring bola pada permainan sepakbola dan observasi motivasi, kerjasama dan perkembangan gerak sepakbola. Penelitian ini adalah PTK (Penelitian Tindakan Kelas) Adapun Subjek dalam penelitian ini adalah siswa kelas VIII 8. SMPN 8 Palopo yang berjumlah 28 siswa yang terdiri dari 13 prempuan dan 15 laki-laki.Hasil penelitian maka dapat disimpulkan bahwa upaya meningkatkan hasil belajar menggiring bola pada permainan sepakbola dengan metode inkuiry pada siswa kelas VIII SMP Negeri 8 Palopo ditandai dengan peningkatan nilai rata-rata siswa. Nilai rata-rata siswa pada kegiatan pratindakan sebesar 70.67 dengan persentase ketuntasan sebesar $42,86 \%$. Kondisi tersebut mengalami peningkatan nilai rata-rata siswa pada siklus I yaitu sebesar 73,74 dan persentase ketuntasan sebesar 60,71\%. Namun, peningkatan tersebut masih belum mencapai target yang ditetapkan sebelumnya. Kemudian setelah melanjutkan ke siklus II nilai rata-rata sepakbola siswa kembali mengalami peningkatan sebesar 80,82 dengan persentase ketuntasan sebesar $85,71 \%$. Hal tersebut menunjukkan bahwa target yang telah ditetapkan sebelumnya sudah tercapai sehingga penelitian dihentikan pada siklus II. Kemampuan menggiring bola pada permainan sepakbola peserta didik meningkat dengan ditandai dengan seluruh peserta didik tuntas KKM (Kriteria Ketuntasan Minimal) yaitu 75.
\end{abstract}

Kata Kunci: Menggiring, Sepakbola, Metode Inkuiry 


\section{Pendahuluan}

Pendidikan merupakan salah satu kegiatan yang sangat penting untuk menciptakan suatu generasi penerus bangsa yang berkualitas. Hal ini berdasarkan Undang-Undang Republik Indonesia No.12 Tahun 2012 Bab 1 Pasal 1 bahwa pendidikan adalah usaha sadar dan terencana untuk mewujudkan suasana belajar dan proses pembelajaran agar peserta didik secara aktif mengembangkan potensi dirinya untuk memiliki pengendaliandiri, kepribadian, kecerdasan, akhlak mulia, serta keterampilan yang dibutuhkan dirinya, masyarakat, bangsa, dan negara.

Perkembangan konsep Pendidikan Jasmani semakin lama telah menunjukkan pergeseran menuju perkembangan yang lebih maju, yang ditandai dengan upaya mengembangkan seluruh kemampuan atau potensi manusia secara utuh.Untuk memberikan gambaran dan pengertian yang lebih jelas maka akan dikemukakan beberapa pengertian tentang Pendidikan Jasmani dari berbagai literatur yang tentu mempunyai pendapat sendiri tentang apa yang dimaksud Pendidikan Jasmani. Pendidikan Jasmani adalah bagian yang terpadu dari proses Pendidikan secara menyeluruh, bidang dan sasaran yang diusahakan adalah perkembangan jasmani, mental, emosional, dan sosial bagi warga negara yang sehat, melalui medium kegiatan jasmani secara efesien, meningkatkan kualitas unjuk kerjanya (performance) kemampuan belajarnya dan kesehatannya.

Kurikulum merupakan penyempurnaan suatu kegiatan pembelajaran yang mencakup beberapa rencana dan pengaturan yang digunakan sebagai pedoman dalam mencapai tujuan pendidikan (Undang-Undang Nomor 20 tahun 2003 tentang Sistem Pendidikan Nasional). Suatu negara menggunakan kurikulum sebagai cara untuk mencapai tujuan pendidikan. Dalam satuan kurikulum pembelajaran Pendidikan Jasmani Olahraga dan Kesehatan pada tingkat SMP, ada beberapa cabang olahraga yang menjadi indikator pencapaian siswa.Salah satunya yaitu cabang olahraga sepakbola.

Sepakbola merupakan permainan invasi yaitu permainan yang memperbolehkan setiap pemain dalam sebuah tim atau regu yang bertanding menyerang memasuki daerah pertahanan lawan, dan setiap pemain dalam sebuah tim berusaha memasukkan bola kegawang lawannya untuk membuat gol atau skor serta menjaga gawangnya dari serangan lawan. Teknik dasar permainan sepakbola merupakan hal yang sangat penting dalam permainan sepakbola kerena itu merupakan hal yang harus dikuasai seorang pemainan apabila ingin bermain bola dengan baik.Salah satu teknik dasar dalam bermain sepakbola yang harus dikuasai setiap pemain yaitu teknik dasar menggiring bola (dribbling).

Sepakbola adalah olahraga yang dimainkan secara beregu/berkelompok yang setiap tim terdiri dari 11 pemain. Menurut Sucipto dkk (2000) dalam jurnal Suratin (2016: 23) menjelaskan bahwa Sepakbola adalah permainan beregu yang masing-masing tim terdiri dari sebelas orang pemain termasuk seoarang penjaga gawang. Menurut Nasution $(2018 ; 4)$ Sepakbola merupakan permainanyangdimainkan oleh duaregu yang masing-masing regu terdiri dari (11) orang pemain, yang lazim disebutdengan kesebelasan.

Sepakbola dalam pendidikan jasmani adalah sebagai mediator untuk mendidik anak agar berkembang kemampuan kognitif, afektif, psikomotor, dan sosialnya. Tujuan dari permainan sepakbola adalah masing-masing regu atau kesebelasan yaitu berusaha menguasai bola, memasukan bola ke dalam gawang lawan sebanyak mungkin, dan berusaha mematahkan serangan lawan untuk melindungi atau menjaga gawangnya agar tidak kemasukan bola.

Salah satu teknik dasar dasar dalam bermain sepakbola yang harus dikuasai setiap pemain yaitu teknik dasar menggiring bola (dribbling).Tidak semua orang dapat 
menggiring bola dengan baik, dalam teknik dasar menggiring bola sebaiknya bola harus dekat dengan kaki.

Menurut Mielke (2003) dalam jurbal Hariadi dkk (2016:64) Menggiring bola (dribbling) adalah teknik dasar dasar dalam sepakbola karena semua pemain harus mampu menguasai bola saat sedang bergerak, berdiri, atau bersiap melakukan operan atau tembakan.

Sedangkan menurut Luxbacher (1998) dalam jurnal Hariadi dkk (2016:64) menjelaskan bahwa "menggiring bola dalam sepakbola memiliki fungsi yang sama dengan bola basket yaitu memungkinkan untuk mempertahankan bola saat berlari melintasi lawan atau maju ke ruang yang terbuka dapat menggunakan berbagai bagian kaki (inside, outside, instep, telapak kaki) untuk mengontrol bola sambil terus menggiring bola".

Hidayat (2019:60) Dalam jurnal Penjaskesrek Menggiring adalah membawa bola sambil berlari dengan berbagai macam teknik sentuhan kaki dengan bola yang bertujuan untuk melewati lawan atau untuk mendapatkan posisi yang tepat guna dapat melakukan teknk gerakan selanjutnya seperti passing atau menendang bola ke gawang.

Metode merupakan suatu cara yang ditempuh dengan sistematis dimana dalam fungsinya terletak suatu tujuan tertentu yang hendak dicapai. Sesuai dengan pernyataan Hamdani (2011:80), "Metode pembelajaran adalah cara yang digunakan guru untuk menyampaikan pelajaran kepada siswa". Menurut Surakhmad (2009) dalam jurnal Nurhayati dkk (2016:76), "Metode pengajaran adalah cara-cara pelaksanaan daripada proses pengajaran atau soal bagaimana teknisnya sesuatu bahan pelajaran diberikan kepada murid-murid di sekolah".

Metode inquiry merupakan salah satu langkah yang dapat ditempuh untuk memperbaiki sekaligus mengingkatkan hasil belajar siswa khususnya pada subtema gaya dan gerak. Menurut Soedanyo (2000) dalam jurnal Nurhayati (2015:77) Inquiry adalah menanyakan, meminta keterangan atau menyelidiki.inkuiri dalam bahasa inggris "Inquiry" berarti pertanyaan, pemeriksaan atau penyelidikan.Sitorus hamidun haji dkk.(2017:171) dalam jurnal internasional "stated that the inquiry motivates and encourages students to actively explore and master the subject matter themselves" yang artinya menyatakan bahwa inkuiry memotivasi dan medorong siswa untuk aktif mengekplorasi dan menguasai materi pembelajaran itu sendiri.

Jihad dkk (2013) dalam jurnal Hutauruk dkk. (2018:123) menyatakan bahwa "Hasil belajar adalah yang dicapai siswa sangat erat kaitannya dengan rumusan tujuan intruksional yang direncanakan guru sebelumnya yang dikelompokkan kedalam tiga kategori yaitu: kognitif, afektif, dan psikomotorik". Wingkel (2011) dalam jurnal Hutauruk dkk. (2018:123) berpendapat bahwa "Hasil belajar adalah perubahan yang mengakibatkan manusia dalam sikap tingkah lakunya". Dari beberapa pendapat di atas saya menyimpulkan bahwa hasil belajar adalah suatu penilaian akhir dari proses dan pengenalan yang telah dilakukan berulang-ulang.

Berdasarkan hasil data jumlah dan persentasi siswa yang mendapatkan nilai baik sebanyak 12 siswa dengan persentasi 42,86\%, siswa yang nilainya kurang sebanyak 16 siswa dengan persentasi $57.14 \%$ Oleh karena itu, untuk mengajarkan siswa bermain sepakbola harus sesuai dengan kurikulum yang berlaku dan pada penelitian ini siswa diharapkan mampu untuk berfikir kritis, analitis, dan sistematis dalam rangka menemukan jawaban secara mandiri dari berbagai permasalahan yang diutarakan. Sehingga pada penelitian kali ini akan menggunakan metode inqury untuk membantu siswa agar mampu 
meningkatkan teknik menggiring dalam permainan sepakbola dengan model dribbling slalom.

Berdasarkan uraian diatas, metode inquiry dengan pembelajaran menggiring bola dan proses pembelajaran sepakbola di sekolah sangatlah berkaitan erat. Berdasarkan uraian diatas, rumusan masalah dalam penelitian ini adalah bagaimana peningkatan kemampuan mengiring bola melalui metode inquiry?. Tujuan penelitian ini adalah untuk mengetahui peningkatan menggiring bola melalui metode inquiry.

\section{Metode}

Desain penelitian menggunakan Penelitian Tindakan Kelas. Dalam tindakan kelas ini, dilaksanakan dalam empat tahap secara bersiklus, yang terdiri atas perencanaan, tindakan observasi dan refleksi.Secara garis besar model penelitian tindakan kelas (PTK) terbagi atas empat tahapan yang lazim dilalui yaitu: (1) perencanaan, (2) pelaksanaan, (3) pengamatan, (4) refleksi.

Metode penelitian ini termasuk kedalam penelitian tindakan kelas (PTK). Menurut Suharsimi Arikunto (2019:1) Penelitian Tindakan Kelas (PTK) adalah penelitian yang memaparkan terjadinya sebab-akibat dari perlakuan, sekaligus memaparkan apa saja yang terjadi ketika perlakuan diberikan, dan memaparkan seluruh proses sejak awal pemberian perlakuan sampai dengan dampak dari perlakuan tersebut. Penelitian ini dilaksanakan dalam empat tahap secara bersiklus, yang terdiri atas perencanaan, tindakan observasi dan refleksi.

Subjek dalam penelitian ini adalah siswa kelas VIII 8. Sejumlah 28 siswa yang terdiri dari 15 prempuan dan 13 laki-laki. Subjek pada penelitian ini, mempunyai kemampuan yang berbeda-beda yakni ada yang mempunyai kemampuan baik, dan kurang. Penelitian ini dilaksanakan di lapangan SMP Negeri 8 Palopo dan dilaksanakan pada bulan AgustusSeptember 2020.

Data berupa angka akan dianalisis denga nanalisis deskriptif komparatif, yaitu membandingkan antara kondisi awal dengan perubahan yang terjadi pada setiap tindakan. Peningkatan yang terjadi akan ditampilkan dalam bentuk table sederhana untuk mendukung deskripsi verbal. Dengan demikian nilai ketuntasan belajar siswa diperoleh melalui rumus sebagai berikut :

1. Tes untuk kerja (Psikomotor) :

$$
\text { Nilai }=\frac{\text { Jumlah skor diperoleh }}{\text { Jumlah skor maksimal }} \quad \times 100
$$

2. Pengamatan sikap (Afektif) :

$$
\text { Nilai }=\frac{\text { Jumlah skor diperoleh }}{\text { Jumlah skor maksimal }} \quad \mathrm{x} 100
$$

3. Tes Siklus/embedded test (kognitif) :

$$
\text { Nilai }=\frac{\text { Jumlah skor diperoleh }}{\text { Jumlah skor maksimal }} \quad \times 100
$$

4. Nilai akhir yang diperoleh siswa :

\section{Nilai tes psikomor + Nilai tes afektif + Nilai tes}

Sumber : Mia Kusmawati (2015:128-130)

Indikator keberhasilan penelitian tindakan kelas ini adalah terjadinya peningkatan pembelajaran menggiringpada olahraga sepakbola menggunakan metode inquiri pada siswakelas VIII.8 SMP Negeri 8 Palopo. Menurut Kriteria Ketuntasan Minimal (KKM) yang 
ditetapkan oleh pihak sekolah, standar ketuntasan minimal untuk tiap individu yaitu nilai 75, dan mencapai tuntas secara klasikal 80\% dari jumlah siswa kelas VIII SMP Negeri 8 Palopo.

\section{Hasil dan Pembahasan}

Kondisi awal kemampuan mengiring bola melalui permainan sepakbola pada siswa kelas VIII.8 SMPN 8 Palopo. Hasil data diperoleh disajikan dalam bentuk tabel sebagai berikut :

Tabel 1: Hasil pengamatan data awal kemampuan menggiring bola melalui permainan sepak bola pada siswa kelas VIII.8 SMPN 8 Palopo.

\begin{tabular}{|r|c|c|c|c|}
\hline No & Rentang Nilai & Kategori & Frekuensi & Persentase \\
\hline 1 & $93-100$ & Sangat Baik & 0 & $0 \%$ \\
\hline 2 & $84-92$ & Baik & 0 & $0 \%$ \\
\hline 3 & $75-83$ & Cukup & 12 & $42,86 \%$ \\
\hline 4 & $<75$ & Kurang & 16 & $57,14 \%$ \\
\hline & & Jumlah & $\mathbf{2 8}$ & $\mathbf{1 0 0 \%}$ \\
\hline
\end{tabular}

Berdasarkan tabel 1 hasil observasi awal sebelum diberikan tindakan dapat dijelaskan bahwa 0 siswayang memiliki kategori sangat baik (0\%), 0 siswa dalam kategori baik (0\%), 12 siswadalam kategori cukup (42,86\%), 16 siswa dalam kategori kurang $(57,14)$. Berdasarkan kriteria ketuntasan minimal yang ditetapkan SMPN 8 Palopo yaitu 75.

\section{Data Awal}



\section{Gambar 1: Diagram batang skor nilai persentase data awal}

\section{Siklus I}

Kegiatan yang telah dilakukan pada siklus I adalah penyajian materi kemampuan menggiring bola pada permainan sepakbola melalui metode inkuiry sebanyak 2 kali pertemuan dan untuk kegiatan tes dilakukan pada pertemuan kedua atau pengambilan nilai aspek psikomotor, afektif, dan kognitif. Berdasarkan kemampuan menggiring bola dalam permainan sepakbola melalui metode inkuiry dapat diklasifikasikan yaitu : sangat baik, baik, cukup, kurang, dan sangat kurang. Selanjutnya dapat dilihat pada tabel 2. 
Journal PANRITA: Journal of Education, Research and Technology

Homepage: https://journal.umpalopo.ac.id/index.php/panrita

Email: mailto:panrita.fkipumpalopo@gmail.com

Tabel 2: Siklus I kemampuan menggiring bola pada permainan sepakbola melalui metode inkuiry pada siswa kelas VIII.8 SMPN 8 Palpo.

\begin{tabular}{|c|c|c|c|c|}
\hline No & Rentang Nilai & Kategori & Frekuensi & $\begin{array}{c}\text { Persenta } \\
\text { se }\end{array}$ \\
\hline 1 & $93-100$ & Sangat Baik & 0 & $0 \%$ \\
\hline 2 & $84-92$ & Baik & 7 & $25 \%$ \\
\hline 3 & $75-83$ & Cukup & 10 & $35,71 \%$ \\
\hline 4 & $<75$ & Kurang & 11 & $39.29 \%$ \\
\hline \multicolumn{2}{|r|}{} & Jumlah & $\mathbf{2 8}$ & $\mathbf{1 0 0 \%}$ \\
\hline
\end{tabular}

Berdasarkan tabel 2. Tampak dari 28 subjek penelitian, terdapat 0siswa yang memiliki kategori baik sekali (0 \%), 7 siswa dalam kategori baik (25\%), 10 siswa yang memiliki dalam kategori cukup (35,71 \%), dan 11 siswa memiliki kategori kurang (39,29\%). Kemampuan menggiring bola dalam permainan sepakbola melalui metode inkuiry pada siklus I dapat dilihat pada diagram batang skor nilai persentase berikut ini :

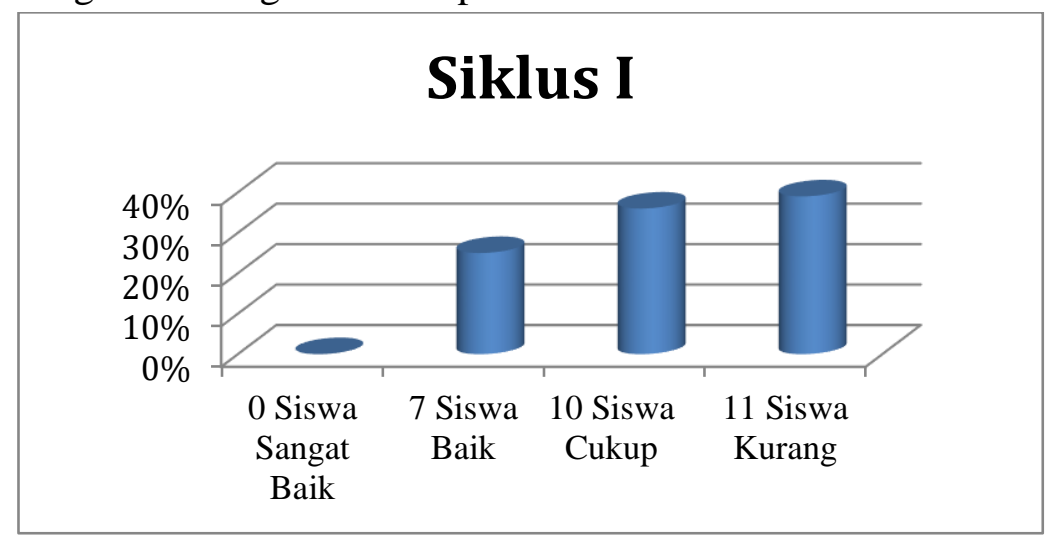

Gambar 2: Diagram batang skor nilai persentase pada siklus I

Tabel 3: Deskripsi ketuntasan siklus I kemampuan menggiring bola pada permaina sepak bola pada siswa kelas VIII.8 SMPN 8 Palopo.

\begin{tabular}{|c|c|c|c|}
\hline $\begin{array}{c}\text { Kritera } \\
\text { Ketuntasan }\end{array}$ & Kategori & Frekuensi & Persentase (\%) \\
\hline $0-74$ & Tidak Tuntas & 11 & $39,29 \%$ \\
\hline $75-100$ & Tuntas & 17 & $60,71 \%$ \\
\hline \multicolumn{2}{|c|}{ Jumlah } & 28 & $100 \%$ \\
\hline
\end{tabular}

Berdasarkan tabel 3. Dari 20 subjek penelitian terdapat 17siswa dengan persentase $60,71 \%$ dalam kategori tuntas dan 11 siswa dengan persentase $39,29 \%$ dalam kategori tidak tuntas pada siklus I. 


\section{Siklus II}

Kegiatan yang telah dilakukan pada siklus II adalah penyajian materi menggiring bola pada permainan sepakbola melalui metode inkuiry sebanyak 2 kali pertemuan untuk tes dilakukan pada pertemuan kedua pengambilan nilai aspek psikomotor, afektif, dan kognitif. Berdasarkan kemampuan menggiring bola pada permainan sepak bola dengan metode inkuiry siswa dapat diklasifikasikan yaitu : sangat baik, baik, cukup, kurang, dan sangat kurang. Selanjutnya dapat dilihat pada tabel 4.4.

Tabel 4: Siklus II kemampuan menggiring bola dalam permainan sepakbola dengan metode inkuiry pada siswa kelas VIII.8 SMPN 8 Palopo

\begin{tabular}{|r|c|c|c|c|}
\hline No & Rentang Nilai & Kategori & Frekuensi & Persentase \\
\hline 1 & $93-100$ & Sangat Baik & 3 & $10,71 \%$ \\
\hline 2 & $84-92$ & Baik & 21 & $75 \%$ \\
\hline 3 & $75-83$ & Cukup & 0 & $0 \%$ \\
\hline 4 & $<75$ & Kurang & 4 & $14.29 \%$ \\
\hline \multicolumn{2}{|r|}{} & Jumlah & $\mathbf{2 8}$ & $\mathbf{1 0 0 \%}$ \\
\hline
\end{tabular}

Berdasarkan tabel 4. Tampak dari 28 siswa, terdapat 3siswa dalam kategori sangat baik $(10,71 \%), 21$ siswa dalam kategori baik (75\%), 0siswa yang memiliki dalam kategori cukup (0\%), dan 4 siswa dalam kategori kurang (14,29\%). Kemampuan dalam menggiring bola pada permainan sepakbola dengan metode pada siklus IIdapat dilihat pada diagram batang skor nilai persentase berikut ini :

\section{Siklus II}

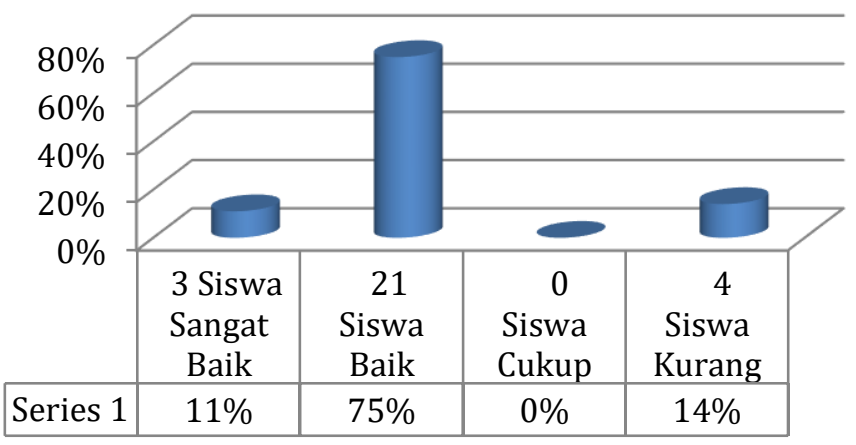

Gambar 4: Diagram batang skor nilai persentase pada siklus II

Berdasarkan kemampuan dalam melakukan menggiring bola dalam permainan sepakbola pada siklus II, maka persentase ketuntasan belajar murid dapat dilihat pada tabel dibawah ini : 
Journal PANRITA: Journal of Education, Research and Technology

Homepage: https://journal.umpalopo.ac.id/index.php/panrita

Email: mailto:panrita.fkipumpalopo@gmail.com

Tabel 5. Deskripsi ketuntasan siklus II kemampuan menggiring bola pada permainan sepak bola pada siswa kelas VIII SMP Negeri 8 Palopo

\begin{tabular}{|c|c|c|c|}
\hline Kritera Ketuntasan & Kategori & Frekuensi & Persentase (\%) \\
\hline $0-74$ & Tidak Tuntas & 4 & $14,29 \%$ \\
\hline $75-100$ & Tuntas & 24 & $85,71 \%$ \\
\hline \multicolumn{2}{|c|}{ Jumlah } & 28 & $100 \%$ \\
\hline
\end{tabular}

Berdasarkan tabel 5. Dari 28 subjek penelitian terdapat 4siswa dengan persentase $14,29 \%$ dalam kategori tidak tuntas dan 24 siswa dengan persentase $85,71 \%$ dalam kategori tuntas pada siklus II.

\section{Perbandingan hasil belajarsiswa siklus I dan siklus II}

Perbandingan kategori ketuntasan hasil belajar kemampuan menggiring bola pada permainan sepakbola melalui metode inquiry pada siswa kelas VIII.8 SMPN 8 Palopo pada siklus I dan II

Tabel 6: Deskripsi ketuntasan belajar pada siklus I \& siklus II kemampuan menggiring bola pada permainan sepakbola melalui siswa kelas VIII.8 SMPN 8 Palopo

\begin{tabular}{|c|c|c|c|c|c|c|}
\hline \multirow{2}{*}{ No } & \multirow{2}{*}{ Nilai } & Kategori & Frekuensi & $\begin{array}{c}\text { Persentase } \\
(\%)\end{array}$ & Frekuensi & $\begin{array}{c}\text { Persentase } \\
(\%)\end{array}$ \\
\cline { 2 - 7 } 1 & $<75,00$ & $\begin{array}{c}\text { Tidak } \\
\text { Tuntas }\end{array}$ & 11 & 39,29 & 4 & 14,29 \\
\hline 2 & $>75,00$ & Tuntas & 17 & 60,71 & 24 & 85,71 \\
\hline \multicolumn{2}{|c|}{ Jumlah } & 20 & 100 & 20 & 100 \\
\hline
\end{tabular}

Peningkatan hasil belajar siswa pada siklus I mencapai rata - rata 60,71\% sedangkan pada siklus II meningkat menjadi $85,71 \%$. Untuk lebih jelasnya dalam mengenai kemampuan menggiring bola pada permainan melalui metode inkuiry pada siswa kelas VIII.8 SMPN 8

Berdasarkan hasil analisis kuantitatif, terlihat pada dasarnya bahwa pelaksanaan pembelajaran melalui metode inquiry memberikan efek pada aspek kemampuan dalam menggiring bola pada siswa kelas VIII.8 SMPN 8 Palopo yang seimbang dan merata, yaitu terjadi peningkatan pada siklus I ke siklus II.

Pada tabel 1 data awal siswa kelas VIII.8 SMPN 8 bahwa 10 siswa dalam kategori tuntas dengan presentase 35,72\% dan 18 siswa dengan persentase 64,28\% dalam kategori tidak tuntas pada saat sebelum penelitian dilaksanakan. Siklus I jumlah siswa yang memiliki nilai tuntas sebamyak 17 siswa dengan presentase 60,71\% dan memiliki 11 siswa yang memiliki nilai tidak tuntas pada siklus I dengan presentase $39,28 \%$. Siklus II siswa dalam kategori tuntas sebanyak 24 siswa dengan persentase $85,71 \%$ dan 4 siswa yang masuk dalam kategori tidak tuntas dengan persentase $14,28 \%$.

Metode inquiry merupakan salah satu metode pembelajaran yang alternatif yang dapat digunakan dalam pembelajaran PJOK, khususnya materi kemampuan menggiring bola pada permainan sepakbola.Penerapan metode inkuiry dapat memacu siswa untuk mengikuti proses 
pembelajaran dengan lebih bersemangat dan serius tanpa takut akan terjadinya cedera serta memperhatikan dengan baik pelajaran yang diajarkan.Berdasarkan hasil penelitian maka dapat dikatakan bahwa melalui metode inkuiry dapat meningkatkan kualitas pembelajaran kemampuan menggiring bola pada permainan sepakbola dengan metode inkury pada siswa kelas VIII.8 SMPN 8 Palopo

\section{Kesimpulan}

Simpulan pada penelitian ini bahwa pembelajaran sepakbola yang telah diberikan cara menggiring bola dalam permainan sepakbola pada siswa kelas VIII.8 SMPN 8 Palopo. Dari hasil analisis yang diperoleh terdapat peningkatan dari kondisi awal ke siklus I dan siklus II, untuk ketiga aspek (kognitif, afektif dan psikomotor). Pada siklus I yang dimana dari 28 subjek penelitian terdapat 17 siswa dengan persentase $60,71 \%$ dalam kategori tuntas dan 11 siswa dengan persentase 39,29\% dalam kategori tidak tuntas. Karna masih belum mencapai nilai klasikal dari jumlah keseluruhan siswa yaitu $80 \%$, maka dilanjut ke siklus II. Sehingga hasil yang diperoleh siklus II dari 28 subjek penelitian terdapat 4 siswa dengan persentase 14,29\% dalam kategori tidak tuntas dan 24 siswa dengan persentase 85,71\% dalam kategori tuntas. Hasil penelitian yang dapat disimpulkan bahwa pembelajaran Pendidikan Jasmani, Olahraga dan Kesehatan (PJOK) melalui metode inquiry dapat meningkatkan kemampuan dalam menggiring bola pada permainan sepakbola dengan pada siswa kelas VIII.8 SMPN 8 Palopo. Diharapkan dapat menjadikan sebagai bahan pertimbangan untuk meningkatkan pembelajaran pendidikan jasmani, olahragan dan rekreasi khususnya pada cabang permainan sepakbola diharapkan dapat mengembangkan suatu model atau metode permainan keterampilan gerak yang lebih menarik lainnya untuk digunakan dalam pembelajaran sehingga lebih meningkatkan minat siswa dalam melakukan pembelajaran serta dapat mengembangkan metode pembelajaran dengan mengkaji pembelajaran secara mendalam.

\section{Daftar Rujukan}

AB Suid, Yusuf Nasir M, dan Nurhayati 2016. Pengaruh Metode Pembelajaran Inkuiri Pada Subtema Gerak Dan Gaya Terhadap Hasil Belajar Siswa Kelas Iv Sdn 16 Banda Aceh. Jurnal Pesona Dasar3 (4) 73-83

Adiele Dube, , D. Gundani dan Morgan Patrick 2018. Assessing Management Practices of Sport Facilities and Equipment by the Municipality Council. International Journal of Science and Healthcare Research.3 : 2 April-June 2018.

Arikunto, S dkk. 2019. Penelitian Tindakan Kelas. Editor Suryani. Cetakan 3. PT Bumi Aksara. Jakarta.

Artayasa putu I Dkk. 2018. The Effect of Three Levels of Inquiry on the Improvement of

Science Concept Understanding of Elementary School Teacher Candidates. International Journal of Instruction 2018 .11, No.2

Asmara, Wiendhi, Raka dan Hauri. 2015. Pengaruh Latihan Lari Zig-Zag TerhadapKemampuan Menggiring Dalam Permainan Sepak Bola Peserta Ekstrakurikuler Di Smp Negeri 3 Sentolo Kulon Progo.Skripsi Universitas Negeri Yogyakarta.Yogyakarta. 
Bimanggara lucky yoga 2016.Kelengkapan Sarana Dan Prasarana Sepakbola Di Sekolah Sepakbola (Ssb) Se-Kota Yogyakarta Tahun 2016.Skripsi Universitas Negeri Yogyakarta. Yogyakarta

Dahlan Firmansyah 2017. Pengaruh Model Latihan Dribble Slalom Terhadap Keterampilan Menggiring Bola Pemain Sepakbola Syekh Yusuf Football School Kab. Gowa Usia 9 12 Tahun.Jurnal Penjaskesrek 21

Hariadi Imam dan Aprianova Farid 2016. Metode Drill Untuk Meningkatkan Teknik Dasar Menggiring Bola (Dribbling) Dalam Permainan Sepakbola Pada Siswa Sekolah Sepakbola Putra Zodiac Kabupaten Bojonegoro Usia 13-15 Tahun. Skripsi Universitas Negeri Malang. Malang

Hidayat Rachmat. Kontribusi Daya Ledak Tungkai, Kelincahan Dan Keseimbangan Terhadap

Keterampilan Menggiring Bola Pada Permainan Sepakbola Murid SDN 28 Malaka Kec.

Lalabata Kab. Soppeng.Jurnal Penjaskesrek STKIP Mega Rezky Makassar. Volume 5, 1 (Mei) $2019: 56-67$

Hutauruk Pindo, SimbolonRinci. 2018. Meningkatkan Hasil Belajar Siswa Dengan Alat Peraga Pada Mata Pelajaran Ipa Kelas Iv Sdn Nomor 14 Simbolon Purba. SEJ (School Education Journal). 8 (2) 123

Khasanah Uswatun Neni. 2014. Pengaruh Metode Mengajar Dan Media Pembelajaran Terhadap Motivasi Belajar Siswa Kelas X Program Keahlian Administrasi Perkantoran Smk Negeri 1 Yogyakarta. Skripsi Universitas Negeri Yogyakarta.Yogyakarta .

Malasari Azhariat Citra. 2019. Pengaruh Latihan Shuttle-Run Dan Zig-Zag Run Terhadap Kelincahan Atlet Taekwondo. Jurnal Pendidikan Jasmani dan Olahraga.3(1)81-88

Nasution Ahmad 2018. Survei Teknik Dasar Berman Sepak Bola Pada Siswa Smkt Somba Opu Kabupaten Gowa. Jurnal (2018) : 30-35

Nugroho Sugeng, Suparmi dan Sarwanto. 2011.Pembelajaran Ipa Dengan Metode Inkuiri Terbimbing Menggunakan Laboratorium Riil Dan Virtuil Ditinjau Dari Kemampuan Memori Dan Gaya Belajar Siswa. Jurnal Inkuiri 1(3) 235-244

Nurfaidah, Suprapta dan L. Said Muh.2018.Hubungan Kelentukan Dan Kelincahan Terhadap Keterampilan Menggiring Bola Dalam Permainan Sepak Bola Pada Klubred Wood Fc mataram.Jurnal Pendidikan Fisika 6(1)2

Prasetyo Kukuh Soegiyanto dan Irawan Awing Fajar 2020.The Effect of Exercise Methods and Eye-Foot Coordination on Football Passing Accuracy. Journal of Physical Education and Sports 9 (1) (2020) : $82-87$

Sitorus Hamidun Haji, Hasruddin dan Edi Syahmi. 2017. The Influence of Inquiry Learning Model on Student's Scientific Attitudes in Ecosystem Topic at MTs. Daarul Hikmah Sei Alim (Islamic Junior High School) Asahan. International Journal of Humanities Social Sciences and Education. Volume 4, Issue 11, November 2017, PP 170-175.

Subekti Adi Tri Supriyadi, dan Kinanti Gesang Rias 2018. Latihan Dribble Terhadap Kecepatan Dribbling Pada Pemain U14-U15 Ssb Unibraw 82 Kota Malang. Jurnal Kreatif Tadulako.5 (3) 88 
Sujarwadi. Sarjianto, D. 2010. Pendidikan Jasmani Olahraga dan Kesehatan. Editor Fitriani Lestari H Dan Retno Hastuti. Pusat Perbukuan Kementrian Pendidikan Nasional. Jakarta.

Sulastri, Imran, dan Firmansyah Arif 2014. Meningkatkan Hasil Belajar Siswa Melalui Strategi Pembelajaran Berbasis Masalah Pada Mata Pelajaran IPS di Kelas V SDN2 Limbo Makmur Kecamatan Bumi Raya. Jurnal Kreatif Tadulako.3 (1) 92

Suratin. 2016. Upaya Meningkatkan Hasil Pembelajaran Passing Sepak Bola Melalui Pendekatan Permainan Bolbum Pada Siswa Kelas V Sd Negeri Lesanpuro Kajoran Tahun Pelajaran 2015/2016. Skripsi. Universitas Negeri Semarang. Semarang.

Widodo dan widayanti luis 2012. Peningkatan Aktivitas Belajar Dan Hasil Belajar Siswa Dengan Metode Problem Based Learning Pada Siswa Kelas Viia Mts Negeri Donomulyo Kulon Progo Tahun Pelajaran 2012/2013. Junal Pendidikan 1(2) 23 